\title{
CYP1A1 and CYP2E1 polymorphism frequencies in a large Brazilian population
}

\author{
Renata dos Santos Coura ${ }^{1}$, Christiane de Fátima Silva Marques ${ }^{2}$, Rosalina J. Koifman ${ }^{3}$, Sergio Koifman ${ }^{3}$, \\ Pedro Hernan Cabello ${ }^{2}$ and Ana Hatagima ${ }^{2}$ \\ ${ }^{1}$ Programa de Pós-graduação em Genética e Biologia Molecular, Universidade Federal \\ do Rio Grande do Sul, Porto Alegre, RS, Brasil. \\ ${ }^{2}$ Laboratório de Genética Humana, Departamento de Genética, Instituto Oswaldo Cruz, Rio de Janeiro, \\ RJ, Brasil. \\ ${ }^{3}$ Departamento de Epidemiologia e Métodos Quantitativos em Saúde, Escola Nacional de Saúde Pública, \\ Rio de Janeiro, RJ, Brasil.
}

\begin{abstract}
The enzymes encoded by the polymorphic genes CYP1A1 and CYP2E1 play an important role in the activation and inactivation of xenobiotics. These enzymes have been associated with xenobiotic-induced diseases, such as cancer, therapeutic failure and adverse effects of drugs. The aim of the present study was to determine the allelic and genotypic frequencies of these polymorphisms in a large, ethnically mixed Brazilian population sample from Rio de Janeiro. Polymorphisms CYP1A1 and CYP2E1 were determined in 870 unrelated individuals by PCR-RFLP analysis in peripheral blood DNA. The observed allelic frequencies were 0.90 for $C Y P 1 A 1^{*} 1 A$ and 0.95 for $C Y P 2 E 1 * 1 A$, in the total sample. The allelic frequency of $C Y P 1 A 1^{\star} 2 C$ in "pardos" $(0.13)$ and Brazilian whites $(0.11)$ was higher than in Caucasians (0.05), which may be a result of the Amerindian genetic component, that presents the highest frequency of this allele observed up to now. The genotype distributions for both polymorphisms were in Hardy-Weinberg equilibrium and were statistically different between males and females, and among ethnic groups.
\end{abstract}

Key words: cytochromes P450, CYP1A1, CYP2E1, Brazil.

Received: December 13, 2005; Accepted: July 4, 2006.

\section{Introduction}

Cytochromes P450 (P450 or CYP) constitute the most important phase I enzyme group responsible for the metabolism of endogenous and exogenous (xenobiotics) substances. These detoxification enzymes are essential to the maintenance of an individual's health and well-being. CYP1A1 plays a key role in phase I metabolism of polycyclic aromatic hydrocarbons to their ultimate DNAbinding forms (McManus et al., 1990), and CYP2E1 is an ethanol-inducible enzyme important for the metabolism of ethanol, paracetamol, N-nitrosamines and a number of organic solvents (Guengerich et al., 1991). A great part of the current research focuses on the role that P450 plays in the metabolism of chemical compounds, due to its importance in pharmacogenetics and in the susceptibility to environment-related diseases (Hasler, 1999).

Send correspondence to Ana Hatagima. Departamento de Genética, Instituto Oswaldo Cruz, Pavilhão Leônidas Deane, sala 611-C, Avenida Brasil 4365, 21045-900 Rio de Janeiro, RJ, Brasil. E-mail: anah@ioc.fiocruz.br.
A great part of the interindividual and interethnic differences in relation to xenobiotic effects is now attributable to genetic differences in their metabolism. Mutations in a gene coding for an enzyme that metabolizes these substances can give rise to enzyme variants with higher, lower or no activity, or may have no effect at all on enzyme activity (Hasler, 1999). Thus, individuals with elevated activation and low detoxifying potentials could be expected to be more susceptible to cancer (Ingelman-Sundberg, 2002). Many studies have produced conflicting results (d'Errico et al., 1996; Agundez, 2004), which is probably in part because of the low penetrance of this class of susceptibility genes (Garte et al., 2001). In addition, other studies have demonstrated that allele frequencies of metabolic genes are not randomly distributed throughout the human population, but follow specific ethnic and geographic patterns (Garte, 1998; Quinones et al., 1999; Garte et al., 2001; Roy et al., 2001). A small number of studies using large database has allowed for a more precise estimate of the population-specific frequency for these polymorphisms in normal control samples (Garte et al., 2001). These polymorphisms 
are well characterized in some populations, especially Caucasians, but little is known about them in other ethnic groups. Brazilians form one of the most heterogeneous populations in the world, basically the result of a mixture between Caucasians, Africans and native Amerindians (Krieger et al., 1965; Carvalho-Silva et al., 2001). Besides the fact that the ethnic mixture is very pronounced in Brazil, it can vary a lot from region to region. In Rio de Janeiro, for example, the population derives from the mixture of $40 \%$ Caucasians, 52\% Africans, and 8\% Amerindians (LopezCamelo et al., 1996), whereas Caucasians are predominant in the Brazilian South (Marrero et al., 2005).

We present here a descriptive analysis of two polymorphic genes of the cytochrome $\mathrm{P} 450$ group of enzymes, CYP1A1 (exon 7) and CYP2E1 (RFLP PstI), in a large sample of the Rio de Janeiro population.

\section{Material and Methods}

\section{Samples}

Blood samples were collected from 663 unrelated blood donors at the Clementino Fraga Filho Hospital Blood Bank and from 207 healthy individuals from the Orthopedics and Traumatology Hospital of Rio de Janeiro, Brazil. Since these two groups of individuals were homogeneous in relation to the allelic and genotypic frequencies of CYP1A1 and CYP2E1, and both were in Hardy-Weinberg equilibrium (HWE), they were joined into one group, totalizing 870 individuals (mean age $=40$ years; $65 \%$ males). Of this total, 560 individuals were classified, by skin color and other physical traits, as whites (Caucasians, mainly Portuguese descendents); 181 as "pardos" (ethnic mixture of Europeans, Africans and Amerindians); and 129 as blacks (African descendants), based on the official Brazilian census categorization. The Ethics Committees of the institutions involved approved this study, and informed consent was obtained from all participating individuals.

\section{Genotype analysis}

Genomic DNA was isolated from peripheral blood according to the method described by Lahiri and Nurnberger (1991). Genotypes CYP2E1 (Pst I) and CYP1A1 (exon 7) were identified by PCR-restriction fragment length polymorphisms (PCR-RFLP), and the primer sequences were those reported by Sugimura et al. (1995) and Katoh et al. (1995), respectively. CYP1A1 polymorphism was detected in a Hinc II polymorphism assay, using a primer with a single base pair mismatch: 5'-GTCTCCC TCTGGTTACAGGA-3' (sense) and 5'GAAAGACCTC CCAGCGGTCA-3' (antisense). Amplicons (171 bp) were digested overnight (at $37^{\circ} \mathrm{C}$ ) with endonuclease Hinc II, which allows the distinction between the restriction sites on alleles CYP1A1*1A (139 bp and $32 \mathrm{bp}$ fragments) and CYP1A1*2C (120bp, 32bp and 19 bp fragments). The digestion product was analyzed by electrophoresis in a $10 \%$ polyacrylamide gel. For CYP2E1 genotyping, primers 5'-CCAGTCGAGTCTACATTGTCA-3' (sense) and 5'TTCATTCTGTCTTCTAATGG-3' (anti-sense) were used to amplify a $410 \mathrm{bp}$ fragment in CYP2E1, which includes a Pst I restriction site (Hayashi et al., 1991). PCR products were digested with Pst I (New England Biolabs ${ }^{\mathrm{TM}}$ ), according to the manufacturer's recommendations, and then subjected to electrophoresis in 3\% agarose gel. A $410 \mathrm{bp}$ non-digested fragment corresponds to the $C Y P 2 E 1 * 1 A$ allele, and two fragments of 290 and $120 \mathrm{bp}$ correspond to the CYP $2 E 1 * 5 B$ allele.

\section{Statistical analysis}

The maximum likelihood method was used to estimate the allele frequencies, and the goodness of fit of the genotype distribution to the Hardy-Weinberg equilibrium was tested by chi-square. Comparisons between the different ethnic groups or sexes were performed through contingency tables analyzed by chi-square tests.

\section{Results}

The distribution of the 870 individuals according to sex, age, ethnicity and genotypes is presented in Table 1. In the total sample, the observed genotype frequencies of CYP1A1 were $80.3 \%$ for $1 \mathrm{~A} / 1 \mathrm{~A}, 18.7 \%$ for $1 \mathrm{~A} / 2 \mathrm{C}$, and $1.0 \%$ for $2 \mathrm{C} / 2 \mathrm{C}$ mutant homozygotes, and for CYP2E1 they were $91.4 \%$ for $1 \mathrm{~A} / 1 \mathrm{~A}, 8.4 \%$ for $1 \mathrm{~A} / 5 \mathrm{~B}$, and $0.2 \%$ for $5 \mathrm{~B} / 5 \mathrm{~B}$ mutant homozygotes. In the total sample, the allele frequencies ( \pm standard error) were $0.10 \pm 0.007$ for $C Y P 1 A 1 * 2 C$ and $0.04 \pm 0.005$ for $C Y P 2 E 1 * 5 B$. The mean age was $39.58 \pm 13.73$, and there were no significant differences in genotype frequencies among the five age classes for both polymorphisms: CYP1A1, $\mathrm{p}=0.646$; and CYP2E1, $\mathrm{p}=0.960$ (Table 1). On the other hand, statistically significant differences were observed in the genotype frequencies for CYP1A1 and CYP2E1 in relation to ethnicity $(p=0.015)$, and between males and females for CYP1A1 $(p=0.045)$ and CYP2E1 $(p=0.005)$. In the total sample and within the three ethnic groups (whites, "pardos" and blacks), the genotype distribution was in HardyWeinberg equilibrium.

Table 2 shows the allelic frequencies of CYP1A1 and CYP2E1 stratified by ethnicity and compared with other Brazilian populations and different ethnic groups. The allelic frequency of $C Y P 1 A 1^{*} 1 A$ in the present study was $0.893 \pm 0.009$ in whites, $0.870 \pm 0.017$ in "pardos", and $0.953 \pm 0.13$ in blacks. For $C Y P 2 E 1 * 1 A$, frequencies of $0.964 \pm 0.005,0.928 \pm 0.013$, and $0.957 \pm 0.013$ were observed in whites, "pardos" and blacks, respectively.

\section{Discussion}

The P450s of families 1-3, that include CYP1A1 and CYP2E1, are responsible for $70-80 \%$ of all phase I-dependent metabolism of clinically used drugs (Bertz and Gran- 
Table 1 - Distribution of genotypes CYP1A1 and CYP2E1 according to sex, age and ethnicity in a Rio de Janeiro population sample.

\begin{tabular}{|c|c|c|c|c|c|c|}
\hline \multirow[b]{2}{*}{ Sex } & \multicolumn{3}{|c|}{ CYP1A1 genotype frequencies $\mathrm{N}(\%)$} & \multicolumn{3}{|c|}{ CYP2E1 genotype frequencies N (\%) } \\
\hline & $1 \mathrm{~A} / 1 \mathrm{~A}$ & $1 \mathrm{~A} / 2 \mathrm{C}$ & $2 \mathrm{C} / 2 \mathrm{C}$ & $1 \mathrm{~A} / 1 \mathrm{~A}$ & $1 \mathrm{~A} / 5 \mathrm{~B}$ & $5 \mathrm{~B} / 5 \mathrm{~B}$ \\
\hline Male & $442(79)$ & $116(20)$ & $3(1)$ & $500(89)$ & $59(10)$ & $2(1)$ \\
\hline \multirow[t]{2}{*}{ Female } & $257(83)$ & $47(15)$ & $5(2)$ & $295(95)$ & $14(5)$ & $0(0)$ \\
\hline & \multicolumn{3}{|c|}{$\chi_{2}^{2}=6.198 \mathrm{p}=0.045$} & \multicolumn{3}{|c|}{$\chi_{2}^{2}=10.488 \mathrm{p}=0.005$} \\
\hline \multicolumn{7}{|c|}{ Age (years) } \\
\hline $18-27$ & $157(79.7)$ & $39(19.8)$ & $1(0.5)$ & $180(91.4)$ & $16(8.1)$ & $1(0.5)$ \\
\hline $28-37$ & $184(78.6)$ & $46(19.7)$ & $4(1.7)$ & $212(90.6)$ & $21(9.0)$ & $1(0.4)$ \\
\hline $38-47$ & $169(81.6)$ & $36(17.4)$ & $2(1.0)$ & $190(91.8)$ & $17(8.2)$ & $0(0.0)$ \\
\hline $48-57$ & $97(78.2)$ & $27(21.8)$ & $0(0.0)$ & $115(92.7)$ & $9(7.3)$ & $0(0.0)$ \\
\hline \multirow[t]{2}{*}{$\geq 58$} & $92(85.2)$ & $15(13.9)$ & $1(0.9)$ & $98(90.7)$ & $10(9.3)$ & $0(0.0)$ \\
\hline & \multicolumn{3}{|c|}{$\chi_{8}^{2}=6.009 p=0.646$} & \multicolumn{3}{|c|}{$\chi_{8}^{2}=2.523 \mathrm{p}=0.96$} \\
\hline \multicolumn{7}{|c|}{ Ethnic Group } \\
\hline Whites & 445 (79) & $110(20)$ & $5(1)$ & $520(93)$ & $40(7)$ & $0(0)$ \\
\hline "Pardos" & $137(76)$ & $41(23)$ & $3(2)$ & $157(87)$ & $22(12)$ & $2(1)$ \\
\hline Blacks & $117(91)$ & $12(9)$ & $0(0)$ & $118(91)$ & $11(9)$ & $0(0)$ \\
\hline & \multicolumn{3}{|c|}{$\chi_{4}^{2}=12.38 \mathrm{P}=0.015$} & \multicolumn{3}{|c|}{$\chi_{4}^{2}=12.272 \mathrm{p}=0.015$} \\
\hline \multicolumn{7}{|c|}{ Total Sample } \\
\hline & $699(80.3)$ & $163(18.7)$ & $8(1.0)$ & $795(91.4)$ & $73(8.4)$ & $2(0.2)$ \\
\hline & \multicolumn{3}{|c|}{$\chi_{1}^{2}(\mathrm{HWE})=0.197 \mathrm{p}=0.660$} & \multicolumn{3}{|c|}{$\chi_{1}^{2}(\mathrm{HWE})=0.056 \mathrm{p}=0.810$} \\
\hline
\end{tabular}

HWE $=$ Hardy-Weinberg equilibrium .

Table 2 - Allele frequencies of Cyp1A1 (exon 7) and CYP2E1 (Pst I) in different ethnic groups.

\begin{tabular}{|c|c|c|c|c|c|}
\hline \multirow[b]{2}{*}{ Gene } & \multirow[b]{2}{*}{ Ethnic groups } & \multirow[b]{2}{*}{$\mathrm{N}$} & \multicolumn{3}{|c|}{ Allele frequencies } \\
\hline & & & $C Y P 1 A 1 * 1 A$ & $C Y P 1 A 1 * 2 C$ & Reference \\
\hline \multirow[t]{9}{*}{ CYP1A1 } & Whites & 560 & 0.89 & 0.11 & Present paper \\
\hline & "Pardos" & 181 & 0.87 & 0.13 & Present paper \\
\hline & Blacks & 129 & 0.95 & 0.05 & Present paper \\
\hline & South Amerindians & 257 & - & $(0.54-1.0)$ & Gaspar et al. (2002) \\
\hline & Brazilians (RJ) & 108 & 0.91 & 0.09 & Sugimura et al. (1995) \\
\hline & Brazilians (SP) & 221 & 0.83 & 0.17 & Burim et al. (2004) \\
\hline & Caucasians & 4790 & 0.95 & 0.05 & Garte et al. (2001) \\
\hline & Africans & 481 & 0.97 & 0.03 & Garte et al. (2001) \\
\hline & Asians & 1132 & 0.77 & 0.23 & Garte et al. (2001) \\
\hline \multirow[t]{11}{*}{ CYP2E1 } & & & $C Y P 2 E 1 * 1 A$ & $C Y P 2 E 1 * 5 B$ & \\
\hline & Whites & 560 & 0.96 & 0.04 & Present paper \\
\hline & "Pardos" & 181 & 0.93 & 0.07 & Present paper \\
\hline & Blacks & 129 & 0.96 & 0.04 & Present paper \\
\hline & Brazilians (Caucasians) & 206 & 0.95 & 0.05 & Gattas \& Soares-Vieira (2000) \\
\hline & Brazilians (African descendants) & 86 & 0.94 & 0.06 & Gattas \& Soares-Vieira (2000) \\
\hline & Brazilians (RJ) & 108 & 0.94 & 0.06 & Sugimura et al. (1995) \\
\hline & Brazilians (SP) & 221 & 0.94 & 0.06 & Burim et al. (2004) \\
\hline & South Amerindians & 257 & $0.58-0.98$ & $(0.02-0.42)$ & Gaspar et al. (2002) \\
\hline & Caucasians & 1454 & 0.96 & 0.04 & Garte et al. (2001) \\
\hline & Asians & 719 & 0.77 & 0.23 & Garte et al. (2001) \\
\hline
\end{tabular}


neman, 1997; Evans and Relling, 1999) and participate in the metabolism of a huge number of xenobiotic chemicals (Ingelman-Sundberg, 2002). The metabolic activation of precarcinogens and drugs might have toxic or carcinogenic effects. The vast interindividual variation in human drug metabolism has been a major problem for the drug industry and for the physicians, because this variation can lead to a variety of outcomes, which include therapeutic failure, adverse effects, and toxicity in selected individuals undergoing treatment, that are difficult to foresee (IngelmanSundberg, 2002). The type and prevalence of allelic variants present in an individual or in a population can influence the pharmacological and toxicological effects of drugs, toxins and carcinogens, leading to interindividual and interethnic differences (Kalow and Bertilsson, 1994).

Considering that the allelic and genotypic frequencies of metabolic genes vary throughout the human population according to specific ethnic and geographic patterns (Garte, 1998; Quinones et al., 1999; Garte et al., 2001), acquiring knowledge about them is an important task, not only for disease association studies, but also for the evaluation of chemotherapy and adverse drug reactions.

Here, we determined the allelic and genotypic frequency distribution of polymorphisms CYP1A1 (exon 7) and CYP2E1 (Pst I) in a large Brazilian population sample from Rio de Janeiro. The allelic frequency of $C Y P 1 A 1 * 2 C$ in the total sample $(0.10)$ was similar to another one from Rio de Janeiro (0.09) studied by Sugimura et al. (1995), but lower than the results found in São Paulo $(0.17)$ by Burim et al. (2004). When the total sample was stratified by ethnicity and compared with the results observed by Garte et al. (2001), the frequency in whites (0.11) was higher than in Caucasians (0.05), but in blacks (0.05) the frequency seemed similar to Africans (0.03). The highest $C Y P 1 A 1 * 2 C$ frequency $(0.13)$ was observed in "pardos", and was probably influenced by the Amerindian genetic component, which presents the highest frequency of this allele observed up to now (Table 2). In fact, studies have shown that tri-hybrid miscegenation occurs in the Brazilian population in different proportions of the three main groups (Caucasians, Africans and Amerindians) around Brazil (Krieger et al., 1965; Lopez-Camelo et al., 1996; Carvalho-Silva et al., 2001; Parra et al., 2003), which could explain the geographic differences observed in the genetic frequencies.

The frequency observed in the present study for $C Y P 2 E 1 * 5 B(0.04)$ was equal to that of Caucasians (Garte et al., 2001) and similar to the results of Sugimura et al. (1995), Gattas and Soares-Vieira (2000) and Burim et al. (2004) in other Brazilian populations. After stratification, the $C Y P 2 E 1 * 5 B$ allele frequency was the same (0.04) in whites and blacks, and higher in "pardos" (0.7). Similarly to allele $C Y P 1 A 1^{*} 2 C$, the higher frequency of allele $C Y P 2 E 1 * 5 B$ in "pardos" may have been influenced by Amerindian miscegenation, as this allele is also common in
Amerindians (Muñoz et al., 1998; Gaspar et al., 2002). The genetic contribution of Amerindians in the population of Rio de Janeiro is relatively low (8\%) (Lopez-Camelo et al., 1996), but the high frequency of these alleles in Amerindians (Muñoz et al., 1998; Gaspar et al., 2002) might have influenced significantly the final frequency. Nevertheless, we cannot forget that the allele frequency of $C Y P 2 E 1 * 5 B$ was very low, and that this result might have occurred by chance or due to a type I statistical error.

Ethnic differences in metabolic polymorphisms have been previously reported (Muñoz et al., 1998; Garte, 1998; Quinones et al., 1999; Garte et al., 2001) and our results corroborate the ethnic difference in the allelic frequency of CYP1A1 (éxon 7) between Caucasians (or whites) and Africans (blacks). Polymorphisms CYP1A1 and CYP2E1 showed a good fit to Hardy-Weinberg's genetic equilibrium model in relation to the observed and expected genotype frequencies, both in the total sample and in the stratified ethnic sub-groups.

Age effects on the allelic and genotypic frequencies were not observed in the present study. On the other hand, sex differences were found for CYP1A1 and CYP2E1, and this effect has already been noted for CYP1A1 in cancer patients, but not in control populations (Dresler et al., 2000). The basis for the sex differences in the genotype frequency distributions of CYP1A1 and CYP2E1 is unknown, but their significance can be due to a type I statistical error.

This study provides basic information about the allele and genotype frequency distributions of two specific polymorphisms, CYP1A1 (exon 7) and CYP2E1 (Pst I), in the population of Rio de Janeiro. These frequencies may be useful as a reference for future studies about cancer susceptibility, therapeutic failure and/or adverse effects of drugs.

\section{Acknowledgments}

We thank Dr. Marcos Palatnik, C. Nogueira, Dr. Emilson de Queiros and Dr. Fernando Dias for the generous gift of blood samples, and Tula H. Teixeira for revising the English manuscript. This study was supported by grants from Fundação Oswaldo Cruz (Fiocruz) and Conselho Nacional de Desenvolvimento Científico e Tecnológico (CNPq).

\section{References}

Agundez JA (2004) Cytochrome P450 gene polymorphism and cancer. Curr Drug Metab 5:211-224.

Bertz RJ and Granneman GR (1997) Use of in vitro and in vivo data to estimate the likelihood of metabolic pharmacokinetic interactions. Clin Pharmacokinet 32:210-258.

Burim RV, Canalle R, Martinelli Ade L and Takahashi CS (2004) Polymorphisms in glutathione S-transferases GSTM1, GSTT1 and GSTP1 and cytochromes P450 CYP2E1 and CYP1A1 and susceptibility to cirrhosis or pancreatitis in alcoholics. Mutagenesis 19:291-298. 
Carvalho-Silva DR, Santos FR, Rocha J and Pena SD (2001) The phylogeography of Brazilian Y-chromosome lineages. Am J Hum Genet 68:281-286.

Dresler CM, Fratelli C, Babb J, Everley L, Evans AA and Clapper ML (2000) Gender differences in genetic susceptibility for lung cancer. Lung Cancer 30:153-160.

d'Errico A, Taioli E, Chen X and Vineis P (1996) Genetic metabolic polymorphisms and the risk of cancer: A review of the literature. BioMarkers 1:149-173.

Evans W and Relling MV (1999) Pharmacogenomics: Translating functional genomics into rational therapeutics. Science 286:487-491.

Garte S (1998) The role of ethnicity in cancer susceptibility gene polymorphisms: The example of CYP1A1. Carcinogenesis 19:1329-1332.

Garte S, Gaspari L, Alexandrie AK, Ambrosone C, Autrup H, Autrup JL, Baranova H, Bathum L, Benhamou S, Boffetta P, Bouchardy C, Breskvar K, Brockmoller J, Cascorbi I, Clapper ML, Coutelle C, Daly A, Dell'Omo M, Dolzan V, Dresler CM, Fryer A, Haugen A, Hein DW, Hildesheim A, Hirvonen A, Hsieh LL, Ingelman-Sundberg M, Kalina I, Kang D, Kihara M, Kiyohara C, Kremers P, Lazarus P, Le Marchand L, Lechner MC, van Lieshout EM, London S, Manni JJ, Maugard CM, Morita S, Nazar-Stewart V, Noda K, Oda Y, Parl FF, Pastorelli R, Persson I, Peters WH, Rannug A, Rebbeck T, Risch A, Roelandt L, Romkes M, Ryberg D, Salagovic J, Schoket B, Seidegard J, Shields PG, Sim E, Sinnet D, Strange RC, Stucker I, Sugimura H, To-Figueras J, Vineis P, Yu MC and Taioli E (2001) Metabolic gene polymorphism frequencies in control populations. Cancer Epidemiol Biomarkers Prev 10:1239-1248.

Gaspar PA, Hutz MH, Salzano FM, Hill K, Hurtado AM, PetzlErler ML, Tsuneto LT and Weimer TA (2002) Polymorphisms of CYP1A1, CYP2E1, GSTM1, GSTT1, and TP53 genes in Amerindians. Am J Phy Anthropol 119:249-256.

Gattas GJ and Soares-Vieira JA (2000) Cytochrome P450-2E1 and glutathione S-transferase mu polymorphisms among Caucasians and mulattoes from Brazil. Occup Med 50:508511.

Guengerich FP (1991) Molecular advances for the cytochrome P-450 superfamily. Trends Pharmacol Sci 12:281-283.

Hasler JA (1999) Pharmacogenetics of cytochromes P450. Mol Aspects Med 20:12-137.

Hayashi S, Watanabe J and Kawajiri K (1991) Genetic polymorphisms in the 5'-flanking region change transcriptional regulation of the human cytochrome P450IIE1 gene. J Biochem 110:559-565.
Ingelman-Sundberg M (2002) Polymorphism of cytochrome P450 and xenobiotic toxicity. Toxicology 181:447-452.

Kalow W and Bertilsson L (1994) Interethnic factor affecting drug response. Adv Drug Rev 25:1-53.

Katoh T, Inatomi H, Nagaoka A and Sugita A (1995) Cytochrome P4501A1 gene polymorphism and homozygous deletion of the glutathione S-transferase M1 gene in urothelial cancer patients. Carcinogenesis 16:655-657.

Krieger H, Morton NE, Mi MP, Azevedo E, Freire-Maia A and Yasuda N (1965) Racial admixture in Northeastern Brasil. Ann Hum Genet 19:113-125.

Lahiri DK and Nurnberger JI (1991) A rapid non-enzymatic method for the preparation of HMW DNA from blood for RFLP studies. Nucleic Acids Res 19:5444.

Lopez-Camelo JS, Cabello PH and Dutra MG (1996) A simple model for the estimation of congenital malformation frequency in racially mixed populations. Braz J Genet 19:659663.

Marrero AR, Das Neves Leite FP, De Almeida Carvalho B, Peres LM, Kommers TC, Da Cruz IM, Salzano FM, Ruiz-Linares A, Da Silva Junior WA and Bortolini MC (2005) Heterogeneity of the genome ancestry of individuals classified as White in the state of Rio Grande do Sul, Brazil. Am J Hum Biol 17:496-506

McManus ME, Burgess WM, Veronese ME, Huggett A, Quattrochi LC and Tukey RH (1990) Metabolism of 2-acetylaminofluorene and benzo(a)pyrene and activation of food-derived heterocyclic amine mutagens by human cytochromes P-450. Cancer Res 50:3367-3376.

Muñoz S, Vollrath V, Vallejos MP, Miquel JF, Covarrubias C, Raddatz A and Chianale J (1998) Genetic polymorphisms of CYP2D6, CYP1A1 and CYP2E1 in the South-Amerindian population of Chile. Pharmacogenetics 8:343-351.

Parra FC, Amado RC, Lambertucci JR, Rocha J, Antunes CM and Pena SD (2003) Color and genomic ancestry in Brazilians. Proc Natl Acad Sci USA 100:177-182.

Quinones L, Berthou F, Varela N, Simon B, Gil L and Lucas D (1999) Ethnic susceptibility to lung cancer: Differences in CYP2E1, CYP1A1 and GSTM1 genetic polymorphisms between French Caucasian and Chilean populations. Cancer Lett 141:167-171.

Roy B, Majumder PP, Dey B, Chakraborty M, Banerjee S, Roy M, Mukherjee N and Sil SK (2001) Ethnic differences in distributions of GSTM1 and GSTT1 homozygous "null" genotypes in India. Hum Biol 73:443-450.

Sugimura H, Hamada GS, Suzuki I, Iwase T, Kiyokawa E, Kino I and Tsugane S (1995) CYP1A1 and CYP2E1 polymorphism and lung cancer, case-control study in Rio de Janeiro, Brazil. Pharmacogenetics 5:S145-S148.

Associate Editor: Francisco Mauro Salzano 